\title{
Evaluation and selection of sustainable suppliers in supply chain using new GP-DEA model with imprecise data
}

\author{
Saeid Jafarzadeh Ghoushchi ${ }^{1} \cdot$ Mehran Dodkanloi Milan $^{1} \cdot$ Mustafa Jahangoshai Rezaee $^{1}$
}

Received: 29 July 2017/ Accepted: 21 October 2017/Published online: 7 November 2017

(C) The Author(s) 2017. This article is an open access publication

\begin{abstract}
Nowadays, with respect to knowledge growth about enterprise sustainability, sustainable supplier selection is considered a vital factor in sustainable supply chain management. On the other hand, usually in real problems, the data are imprecise. One method that is helpful for the evaluation and selection of the sustainable supplier and has the ability to use a variety of data types is data envelopment analysis (DEA). In the present article, first, the supplier efficiency is measured with respect to all economic, social and environmental dimensions using DEA and applying imprecise data. Then, to have a general evaluation of the suppliers, the DEA model is developed using imprecise data based on goal programming (GP). Integrating the set of criteria changes the new model into a coherent framework for sustainable supplier selection. Moreover, employing this model in a multilateral sustainable supplier selection can be an incentive for the suppliers to move towards environmental, social and economic activities. Improving environmental, economic and social performance will mean improving the supply chain performance. Finally, the application of the proposed approach is presented with a real dataset.
\end{abstract}

Mustafa Jahangoshai Rezaee

m.jahangoshai@uut.ac.ir

Saeid Jafarzadeh Ghoushchi

s.jafarzadeh@uut.ac.ir

Mehran Dodkanloi Milan

dodkanloo@yahoo.com

1 Faculty of Industrial Engineering, Urmia University of Technology, Urmia, Iran
Keywords Sustainable supplier selection . Environmental · Economic and social performance · Imprecise data envelopment analysis · Goal programming

\section{Introduction}

Supplier selection can be regarded a crucial operational task in developing sustainable supply chain management (SSCM) (Motwani et al. 1999). SSCM is considered a blend of sustainable development and supply chain management (SCM) by Dyllick and Hockerts (2002) whereby sustainable development is described as integrating environmental, social, and economic aspects. All these factors shall be taken into account for selecting an experienced sustainable supplier who can improve the performance of the supply chain. One section of the process of supplier selection deals with the evaluation as well as the selection of the supplier, which is a central concern for supply chain, production, and the literature of operation management (Govindan et al. 2015). At this time, organizations rely more on the suppliers because of outsourcing initiatives. This can make the selection of their suppliers and their performance evaluation more important. Through the past decades, the concept of sustainability has gained importance for the investigators and intellectuals. This is because of the quick reduction of the natural resources as well as the worries over the imbalance of wealth and the social duties in a corporate environment (Govindan et al. 2013).

Dao et al. (2011) deliberated that this worry has led to the increase in the responsibility of firms and the development of theories to upkeep sustainable administrative decision making. The decision of supplier selection is one of the main matters in SCM to raise the competitive advantage of the firms. For attaining a sustainable supply 
chain, the whole members of the chain, ranging from the suppliers to the top managers, have to be acquainted with sustainability. Although a lot of researches exist on supplier selection, studies on sustainable supplier selection are inadequate (Amindoust et al. 2012). The two subjects of the degree of importance of the selection criteria, and the suppliers' performance based on these criteria are indispensable for the selection of the proper suppliers (Ordoobadi 2009). Proper supplier selection regarding sustainability issues, especially economic, environmental and social, plays an important role in sustainable development (Nourmohamadi Shalke et al. 2017). To evaluate the performance of the suppliers, companies consider criteria such as quality, price, flexibility, and supplier reputation. Sustainability aspects have a serious role in longterm achievement of the SCM and considering social and environmental pressures, the process of buying becomes more complex (Seuring and Müller 2008; Bai and Sarkis 2010). Table 1 demonstrates the criteria for sustainable supplier selection, which is achieved from sustainable supplier selection papers such as: (Govindan et al. 2013; Bai and Sarkis 2010; Büyüközkan and Çifçi 2011; Azadi et al. 2015).

Today, most of the organizations and companies need to have a proper and accurate evaluation of their suppliers to meet their own needs and achieve sustainability in supply chain. In addition, all the economic, social and environmental criteria should be employed in the process of sustainable supplier evaluation to improve the performance of the sustainable supply chain. Therefore, a number of quantitative and qualitative criteria need to be employed in the procedure of evaluation (Govindan et al. 2013). For some of these criteria, a precise quantitative value cannot be applied since some of the data are cardinal or ordinal. Thus, an appropriate mathematical model is needed not only to remove these constraints, but also to meet other objectives of this study.

Several approaches are established to resolve the problem in an efficient manner. The approaches of analytic hierarchy process (AHP), analytic network process (ANP), mathematical programming, neural networks (NN), casebased reasoning (CBR) and fuzzy set theory (FST) are applied in the literature (Guneri et al. 2009). One of the approaches that can be adopted for performance evaluation and selection of the sustainable supplier is DEA as a mathematical programming approach.

DEA was introduced by Charnes et al. (1978). DEA has been largely employed to consider multiple criteria in the problems of decision making evaluation. DEA is a nonparametric LP for evaluating the comparative efficiency of decision making units (DMUs). Through the past three decades, a diversity of DEA models have been applied to evaluate the efficiency of DMUs in various areas. On the
Table 1 Used sustainable supplier selection criteria

\begin{tabular}{|c|c|}
\hline Categories & Criteria \\
\hline Economic & $\begin{array}{l}\text { Cost/price } \\
\text { Quality } \\
\text { Technological capability } \\
\text { Organization and management } \\
\text { Production facilities and capacity } \\
\text { Financial capability } \\
\text { Reliability } \\
\text { Flexibility } \\
\text { Total cost of shipments (TC) } \\
\text { Number of shipments (NS) } \\
\text { Delivery time } \\
\text { Innovativeness }\end{array}$ \\
\hline Environmental & $\begin{array}{l}\text { Environmental costs } \\
\text { Green design } \\
\text { Environmental management system } \\
\text { Environmental competencies } \\
\text { Green R\&D } \\
\text { Pollution control } \\
\text { Green product } \\
\text { Resource consumption } \\
\text { Ozone depleting chemicals } \\
\text { Recycling } \\
\text { Water consumption } \\
\text { Energy consumption } \\
\text { Renewable energy } \\
\text { Number of obtained ISO standards }\end{array}$ \\
\hline Social & $\begin{array}{l}\text { The interests and rights of employees } \\
\text { The rights of stakeholders } \\
\text { Work safety and labor health } \\
\text { Information disclosure } \\
\text { Reputation } \\
\text { Respect for the policies } \\
\text { Local communities' influence } \\
\text { Contractual stakeholders' influence } \\
\text { Employment compensation } \\
\text { Equity labor sources } \\
\text { Disciplinary and security practices } \\
\text { Safety risk } \\
\text { Training }\end{array}$ \\
\hline
\end{tabular}

other hand, DEA might encounter imprecise data (Saen 2009). Despotis and Smirlis (2002) proposed a method to deal with imprecise data in DEA models. Kumar et al. (2014) applied a DEA robust model on the problems of supplier selection. Weber et al. (2000) offered DEA for supplier selection based on multiple criteria and determined yardsticks. Kleinsorge et al. (1992) used DEA to track the suppliers' performance. Talluri et al. (2006) 
suggested a CCDEA model for the selection of suppliers in the presence of stochastic data. Saen (2009) introduced a DEA model for ranking suppliers while we have imprecise data, weight restrictions, and nondiscretionary factors. Toloo and Nalchigar (2011) suggested an IDEA model for the selection of suppliers while both cardinal and ordinal data are present.

The aim of the present paper is to present a new DEA model based on goal programming (GP) for performance evaluation and selection of sustainable suppliers while having both cardinal and ordinal data. Multi-objective model and contrast between multiple objectives, application of imprecise (cardinal and ordinal) data in model, more discrimination power compared to the classical DEA. It has turned it into a suitable way to evaluate the sustainable suppliers' issue.

The rest of the present paper is organized as follows. First, review of the literature is proposed. Followed by introducing the approach for evaluating and selecting the suppliers and then case study together with the concluding remarks is discussed. Finally, summary and conclusion are given.

\section{Literature review}

A number of various approaches are presented for supplier selection. For example, Weber et al. (1998) defined three methods for selecting and negotiating with sellers not yet selected. Additionally, they clarified how two multi-criteria analysis tools, MOP, as well as DEA can be used simultaneously for this process of selection and negotiation under some circumstances. Karpak et al. (2001) introduced one of the decision support systems which were "user friendly" with multiple criteria known as visual interactive goal programming (VIG). VIG makes the presentation of a decision support system for improvements in the decisions of supplier selection. Talluri and Narasimhan (2003) proposed a max-min productivity based method deriving variability measures of vendor performance, which are then used in a nonparametric statistical manner for the identification of groups of vendors to have an effective selection. Kumar et al. (2004) used fuzzy GP method. They formulated a vendor selection problem as a fuzzy mixed integer GP to include the imprecise aspiration levels of the objectives. This consists of three main goals: minimizing the net cost, reducing the net rejections, and minimizing the net late deliveries depending on realistic restrictions over customer's demand, vendor's capacity as well as quota flexibility, purchasing value of items, allocating the budget to the individual seller, etc. After specifying the weights of a selected rank, Liu and Hai (2005) made a comparison of the weighted sum of the selection number of rank vote. They proposed a fresh weighting technique instead of pairwise comparison of AHP for supplier selection. They introduced a simpler technique than AHP known as voting analytic hierarchy process. However, it does not miss the organized method of deriving the weights which are adopted and scored the suppliers' performance. Saen (2007) suggested an original method for supplier selection when there are both ordinal and cardinal data. His method identified best suppliers whose efficiency score is equal to one and is not able to find most efficient supplier. Indeed, using his method, decision maker cannot decide which supplier is the best among other units. Ting and Cho (2008) offered a combined method using LP that blends AHP and LP. The procedure takes both tangible and intangible factors into account in the selection of the best suppliers and in giving them ideal order quantities. The aim is to maximize total purchasing value. Kokangul and Susuz (2009) proposed an integrated AHP with nonlinear integer and MOP. The approach is used under certain limitations including quantity discounts, capacity, and budget to specify the best suppliers and put the optimum order quantities among them. Toloo and Nalchigar (2011) propose an innovative integrated DEA model that can detect the most efficient supplier when there exist both cardinal and ordinal data.

Recently, sustainability aspects have a key role in managing supply chain (Wen et al. 2013). Amindoust et al. (2012) introduced a ranking model based on the fuzzy inference system for selecting the sustainable supplier. For sustainable supplier evaluation, Wen et al. (2013) presented a method based on group decision methods of intuitionistic fuzzy sets. To select the top sustainable suppliers, Azadi et al. (2015) developed an integrated DEA enhanced Russell measure (ERM) model in the fuzzy context.

By studying the literature it can be noticed that the three subjects of mathematical modeling, sustainability in supplier selection and impreciseness of the data are studied more and make the framework of this paper. The main focus of this research is sustainability. The goal is to develop a new model that can respond to all aspects of sustainability, dimensions such as: considering different criteria in the research, using imprecise data in the model, improving the model relative to similar models and, finally, evaluation and ranking of the issue. Meanwhile, supplier selection in the supply chain can be considered as an appropriate topic for analysis and a gap in the researches. It is clear that, taking into account the different criteria in the supplier selection issue, a variety of cardinal and ordinal data can be considered. However, as it was mentioned in the introduction, one of the mathematical programming models that is used quite frequently to solve the supplier selection problem is the DEA model. To increase the performance of this model, in recent years, many 
researchers have attempted to use it alongside other techniques or to develop it. One of the improvements about this model is the DEA model based on GP developed by Bal et al. (2010), They presented this model to raise the DEA model's discrimination power. Nevertheless, due to the mathematical errors discussed in the next part, their model was not employed to solve real problems such as supplier selection. On the other hand, this model is developed and besides using imprecise data, several desirable levels of goal are considered for it.

In the present study, after selecting appropriate criteria from the previous researches and categorizing them based on sustainability, the suppliers are evaluated separately in terms of economic, social and environmental conditions using DEA model with imprecise data. Finally, to have an overall evaluation of the suppliers, it is attempted to develop a comprehensive and consistent model for the selection and evaluation of the sustainable supplier so that it can overcome the weaknesses of classical supplier selection models from different dimensions. In general, the approach employed in the present study has the following features:

- Not only the proposed approach evaluates the suppliers separately from economic, social and environmental dimensions, but also it can have an overall evaluation of the suppliers.

- Proposed model has several levels of goal.

- Model has more discrimination power compared to the classical DEA models.

- Offered model respects both cardinal and ordinal data for sustainable supplier selection.

- Suggested model considers multiple criteria.

\section{Proposed method for supplier selection}

\section{Classical DEA models}

DEA is a method for assessing the effectiveness of DMUs, which was offered by Charnes et al. (1978) (CCR model) and developed by Banker et al. (1984) (BCC model).

Suppose that we have $n$ DMUs, $\left(\mathrm{DMU}_{j}: j=1,2, \ldots, n\right)$ consuming $m$ inputs $\left(x_{i}: i=1,2, \ldots, m\right)$ and producing $s$ outputs $\left(y_{r}: r=1,2, \ldots, s\right)$. When a $\mathrm{DMU}_{o}$ is being evaluated by the CCR model, there is

$$
\begin{aligned}
& \operatorname{Max} z=\sum_{r=1}^{s} u_{r} y_{r 0} \\
& \sum_{i=1}^{m} v_{i} x_{i 0}=1 \\
& \sum_{r=1}^{s} u_{r} y_{r j}-\sum_{i=1}^{m} v_{i} x_{i j} \leq 0 \quad j=1,2, \ldots, n \quad u_{r}, v_{i} \geq 0,
\end{aligned}
$$

where $x_{i j}$ and $y_{r j}$ (all nonnegative) are, respectively, the inputs and outputs of the $\mathrm{DMU}_{j} . v_{i}$ and $u_{r}$ are the input and output weights (known as multipliers). $x_{i o}$ and $y_{r o}$ are the inputs and outputs of $\mathrm{DMU}_{o}$. This assessment is mostly assumed to be founded on a set of cardinal (quantitative) output and input variables. However, in numerous actual applications (particularly supplier selection problems), it is crucial to consider ordinal (qualitative) variables when deciding on the performance of a DMU. It is frequently the case that for a factor such as supplier reputation or supplier's green image, at the most, one can deliver a ranking of the DMUs from the best to the worst in relation to this attribute. In certain conditions, these issues can be quantified in a legitimate manner. However, in most of the cases, this quantification might be superficially forced in the form of a modeling convenience. In circumstances similar to the one noted above, the data for some influence factors (inputs and outputs) may be represented in a better way as rank positions in an ordinal sense instead of a numerical one. Let us refer once more to the instance of supplier reputation. In some situations, the available information could allow the provision of a thorough rank ordering of the DMUs on a factor. Thus, the data might not be precise. To handle imprecise data in DEA, models of imprecise data envelopment analysis (IDEA) were introduced. The related DEA model turns into a nonlinear one when we consider imprecision. This makes its process of solution challenging (Saen 2007). Kim et al. (1999) deliberated that some outputs and inputs are imprecise data and have the forms of bounded, ordinal, and ratio bounded data as follows: Bounded data:

$\underline{y}_{r j} \leq y_{r j} \leq \bar{y}_{r j}, \quad \underline{x}_{i j} \leq x_{i j} \leq \bar{x}_{i j} \quad$ for $r \in \mathrm{BO}, i \in \mathrm{BI}$,

where $y_{r j}$ and $x_{i j}$ represent the lower bounds, $y_{r j}$ and $x_{i j}$ show the upper bounds, and $\mathrm{BO}$ and $\mathrm{BI}$ are the related sets comprising, respectively, the bounded outputs and bounded inputs.

Weak ordinal data:

$y_{r j} \leq y_{r k}, \quad x_{i j} \leq x_{i k} \quad j \neq k \quad r \in \mathrm{DO}, i \in \mathrm{DI}$,

or, to streamline the demonstration,

$y_{r 1} \leq y_{r 2} \leq \cdots \leq y_{r k} \leq \cdots y_{r n} \quad(r \in \mathrm{DO})$,

$x_{i 1} \leq x_{i 2} \leq \cdots \leq x_{i k} \leq \cdots x_{i n} \quad(i \in \mathrm{DI})$,

where DO and DI are the related sets encompassing, respectively, weak ordinal outputs and inputs.

Strong ordinal data:

$$
\begin{aligned}
& y_{r 1}<y_{r 2}<\cdots<y_{r k}<\cdots y_{r n} \quad(r \in \mathrm{SO}) \text {, } \\
& x_{i 1}<x_{i 2}<\cdots<x_{i k}<\cdots x_{i n} \quad(i \in \mathrm{SI}) \text {, }
\end{aligned}
$$

where SO and SI show the related sets that, respectively, include strong ordinal outputs and inputs. 
Ratio bounded data:

$L_{r j} \leq \frac{y_{r j}}{y_{r j 0}} \leq U_{r j} \quad\left(j \neq j_{0}\right) \quad r \in \mathrm{RO}$,

$G_{i j} \leq \frac{x_{i j}}{x_{i j 0}} \leq H_{i j} \quad\left(j \neq j_{0}\right) \quad i \in \mathrm{RI}$,

where $L_{r j}$ and $G_{i j}$ are the lower bounds, and $U_{r j}$ and $H_{i j}$ are the upper bounds. RO and RI are the related sets covering ratio bounded outputs and inputs, respectively.

Zhu (2003) introduced a nonlinear model by adding Eqs. (2)-(8) to model (1) who proposed the following variable change to make it linear:

$X_{i j}=v_{i} x_{i j} \quad \forall i, j$,

$Y_{r j}=u_{r} y_{r j} \quad \forall r, j$.

Applying this variable change, Zhu developed the CCR model and introduced model (11) that can evaluate the units with imprecise data:

$$
\begin{aligned}
& \operatorname{Max} z=\sum_{r=1}^{s} Y_{r_{0}} \\
& \sum_{i=1}^{m} X_{i_{0}}=1 \\
& \sum_{r=1}^{s} Y_{r j}-\sum_{i=1}^{m} X_{i j} \leq 0 \quad j=1,2, \ldots, n \\
& X_{i j}, Y_{r j} \geq 0 \quad \forall i, r \\
& X_{i j}, Y_{r j} \geq 0 \\
& X_{i j} \in D_{i}^{-} \\
& Y_{r j} \in D_{r}^{+},
\end{aligned}
$$

where $D_{i}^{-}$and $D_{r}^{+}$are:

1. Bounded data:

$$
\underline{y}_{r j} u_{r} \leq Y_{r j} \leq \bar{y}_{r j} u_{r}, \underline{x}_{i j} v_{i} \leq X_{i j} \leq \bar{x}_{i j} v_{i} \text {. }
$$

2. Ordinal data:

$$
Y_{r j} \leq Y_{r k}, \quad X_{i j} \leq X_{i k} \quad \forall j \neq k, \forall i, r .
$$

3. Ratio bounded data:

$$
L_{r j} \leq \frac{Y_{r j}}{Y_{r j}} \leq U_{r j}, \quad G_{i j} \leq \frac{X_{i j}}{X_{i j}} \leq H_{i j} \quad\left(j \neq j_{0}\right) .
$$

4. Cardinal data:

$$
Y_{r j}=\hat{y}_{r j} u_{r}, \quad X_{i j}=\hat{x}_{i j} v_{i},
$$

where $\hat{y}_{r j}$ and $\hat{x}_{i j}$ represent cardinal data.

\section{DEA development models}

DEA has turned into a progressively dominant method in analyzing the efficiency of both public and private sector organizations. Nevertheless, certain problems have emerged along with advances in the applications of DEA. Two inter-related problems being known for a long time are the lack of discrimination power and the unrealistic weight dispersion. The problem of lacking discriminating power occurs when there are insufficient DMUs under assessment compared with the total number of inputs-outputs. In such a circumstance, classical DEA models frequently produce solutions that excessively detect most of the DMUs as efficient. To improve the discrimination of DEA, some DEA methods including super efficiency, multiple criteria DEA, and cross efficiency were presented in the literature of DEA (AnguloMeza and Lins 2002). The MCDEA model is one of the enhanced models of DEA which was developed by Li and Reeves (1999). Suppose we have $n$ units with $m$ inputs and $s$ outputs. The model will be as such:

$\min d_{0}\left(\right.$ or $\left.\max \theta_{0}=\sum_{r=1}^{s} u_{r} y_{r 0}\right)$

$\min M$

$\min \sum_{j=1}^{n} d_{j}$

s.t.

$\sum_{i=1}^{m} v_{i} x_{i 0}=1$

$\sum^{s} u_{r} y_{r j}-\sum_{i=1}^{m} v_{i} x_{i j}+d_{j}=0, \quad j=1,2, \ldots, n$

$\stackrel{r^{M}}{M}-d_{j} \geq 0, \quad j=1,2, \ldots n$

$u_{r} \geq 0, \quad r=1,2, \ldots, s$

$v_{i} \geq 0, \quad i=1,2, \ldots m$

$d_{j} \geq 0, \quad j=1,2, \ldots, n$,

where $d_{o}$ represents the deviation variable for $\mathrm{DMU}_{0}$ and $d_{\mathrm{j}}$ shows the deviation variable of $\mathrm{DMU}_{j} . M$ is the maximum deviation variable $\left(\max \left\{d_{\mathrm{j}}\right\}\right)$. The quantity $d_{\mathrm{o}}$, being bounded by the interval $(0,1]$, can be considered an inefficiency measure. In this model, $\mathrm{DMU}_{0}$ is considered efficient if and only if $d_{\mathrm{o}}=-0$ or $\sum_{r=1}^{s} u_{r} y_{r 0}=1$. If $D M U_{0}$ is not efficient, its efficiency score is $1-d_{\mathrm{o}}$. Min $M$ is the second objective function, a min max function that minimizes the maximum deviation variable. The third objective function is min $\sum_{j=1}^{n} d_{j}=1$, a min sum function that minimizes the sum of the deviation variables. After model (16), the first developed model of DEA based on GP was GPDEACCR model introduced by Bal et al. (2010). This model being in fact the GP type of model (17), is described as follows: 
$\min z=\left\{d_{1}^{-}+d_{1}^{+}+d_{2}^{+}+\sum_{j} d_{3 j}^{-}+\sum_{j} d_{j}\right\}$

s.t.

$\sum_{i=1}^{m} v_{i} x_{i 0}+d_{1}^{-}-d_{1}^{+}=1$

$\sum_{r=1}^{s} u_{r} y_{r 0}+d_{2}^{-}-d_{2}^{+}=1$

$\sum_{r=1}^{s} u_{r} y_{r j}-\sum_{i=1}^{m} v_{i} x_{i j}+d_{j}=0 \quad j=1,2, \ldots, n$

$M-d_{j}+d_{3 j}^{-}-d_{3 j}^{+}=0 \quad j=1,2, \ldots, n$

$u_{r} \geq 0 \quad r=1,2, \ldots, s$

$v_{i} \geq 0 \quad i=1,2, \ldots, m$

$d_{j}, d_{3 j}^{+}, d_{3 j}^{-} \geq 0 \quad, \quad j=1,2, \ldots, n$

$d_{1}^{-}, d_{1}^{+}, d_{2}^{-}, d_{2}^{+} \geq 0$,

where for the DMU under assessment, $d_{1}^{-}$and $d_{1}^{+}$are the unwanted deviation variables for the goal that restrains the weighted sum of inputs to unity, $d_{2}^{-}$is the wanted deviation variable for the goal that makes the weighted sum of outputs less than or equal to unity, $d_{2}^{+}$is the unwanted deviation variable for the goal that makes the weighted sum of outputs less than or equal to unity. All $d_{3 j}^{-}$'s are the unwanted deviation variables for the goal (i.e., $M-d_{j} \geq 0 \quad j=1,2, \ldots, n$ ) that make $M$ the maximum deviation, and the whole $d_{3 j}^{+}$, s are the wanted deviation variables for the same goal (i.e., $\left.M-d_{j} \geq 0 \quad j=1,2, \ldots, n\right)$ in which all $d_{j}$ deviation variables are unwanted as well.

\section{Proposed model}

Bal et al. (2010) developed model (17) to expand the discrimination power of classical models of DEA based on GP. Nonetheless, as it was mentioned in the introduction, model (17) is rarely used for real problems due to its inappropriateness and mathematical errors. The constraints of model (17) which are corrected in this article are as follows:

- Violation of the constraint $\sum_{i=1}^{m} v_{i} x_{i 0}=1$.

It is clear that model (17) is grounded on the input-based model of CCR where the total input should be considered as a constant number 1 to maximize the total output. However, in model (17), by minimizing the total deviations $\left(d_{1}^{-}+d_{1}^{+}\right)$this constraint is placed between 0 and 1 . Thus, in cases where performance may be equal to 1 , it is mistakenly considered less than 1 and a correct evaluation is not formed. Thus, we can claim that the total deviations $\left(d_{1}^{-}+d_{1}^{+}\right)$should never be considered in the model. To prove this claim, we act as follows:
According to model (17):

$\sum_{r=1}^{s} u_{r} y_{r 0}+d_{2}^{-}-d_{2}^{+}=1$,

$\sum_{i=1}^{m} v_{i} x_{i 0}+d_{1}^{-}-d_{1}^{+}=1$,

$\sum_{r=1}^{s} u_{r} y_{r j}-\sum_{i=1}^{m} v_{i} x_{i j}+d_{j}=0$.

Now, if relation (ii) is multiplied by $(-1)$, we will have relation (iv):

$-\sum_{i=1}^{m} v_{i} x_{i 0}-\left(d_{1}^{-}-d_{1}^{+}\right)=-1$.

If relations (i) and (iv) are added, we will have:

$\sum_{r=1}^{s} u_{r} y_{r 0}-\sum_{i=1}^{m} v_{i} x_{i 0}+d_{2}^{-}-d_{2}^{+}-\left(d_{1}^{-}-d_{1}^{+}\right)=0$.

Now, suppose $j=0$. Then:

$\sum_{r=1}^{s} u_{r} y_{r 0}-\sum_{i=1}^{m} v_{i} x_{i 0}+d_{0}=0$.

According to relations (v) and (vi) we have

$d_{0}=d_{2}^{-}-d_{2}^{+}-\left(d_{1}^{-}-d_{1}^{+}\right)$.

Now, since the performance of the unit under evaluation $\left(h_{0}\right)$ is equal to $\sum_{r=1}^{s} u_{r} y_{r 0}$, relation (i) can be rewritten as follows:

$h_{0}=\sum_{r=1}^{s} u_{r} y_{r 0}=1-\left(d_{2}^{-}-d_{2}^{+}\right)$.

Since in classical models of DEA we have $h_{0}=1-d_{0}$ and according to relation (viii), we have $d_{0}=d_{2}^{-}-d_{2}^{+}$, then the value of $\left(d_{1}^{-}-d_{1}^{+}\right)$in relation (vii) should be 0 . In this way, relation (ii) in model (17) should not be considered.

- The constraint of the model to use only accurate data.

In fact, there are situations where there is no accurate information about the inputs and outputs of the units. In other words, in some conditions, it is not possible to determine a precise numerical value for some inputs or outputs. In these conditions, we need models to evaluate the performance of decision units considering imprecise units. To do so, the method adopted in model (11) is used which is elaborated in the next parts. So that equations of (12)-(15) have been added. In other words; the new model is a combination of model (11) and goal programming modeling. 
- Being simple and with a single objective.

Most of the DEA models that are used for the evaluation of suppliers are simple and have a single objective. What is striking in real problems is the contrast between multiple objectives in a way that achieving and moving along some of them moves us away from the other objectives. Thus, finding variable sets that can simultaneously follow all objectives, compared to a condition where only one objective can be followed, is difficult and rare. Therefore, in the current study, according to the concepts of the GP model, a model with three economic, social and environmental goal sets is developed based on which, the actual performance for each supplier is selected.

According to the analyses conducted with respect to model (17) above and using model (11), the developed model for unit 0 is presented as follows:

$\min z=\left\{d_{1}^{+}+d_{2}^{+}+d_{3}^{+}+\sum_{j} d_{3 j}^{-}+\sum_{j} d_{j}\right\}$

s.t.

$\sum_{i=1}^{m} X_{i 0}=1 \quad i=1,2, \ldots, m$

$\sum_{r=1}^{s} Y_{r 0}+d_{1}^{-}-d_{1}^{+}=e_{1}^{*} \quad r=1,2, \ldots, s$

$\sum_{r=1}^{s} Y_{r 0}+d_{2}^{-}-d_{2}^{+}=e_{2}^{*}$

$\sum_{r=1}^{s} Y_{r 0}+d_{3}^{-}-d_{3}^{+}=e_{3}^{*}$

$\sum_{r=1}^{s} Y_{r j}-\sum_{i=1}^{m} X_{i j}+d_{j}=0 \quad j=1,2, \ldots, n$

$M-d_{j}+d_{3 j}^{-}-d_{3 j}^{+}=0 \quad j=1,2, \ldots, n$

$X_{i j} \in D_{i}^{-}$

$Y_{r j} \in D_{r}^{+}$

$X_{i j} \geq \varepsilon \quad \forall i, j$

$Y_{r j} \geq \varepsilon \quad \forall r, j$

$d_{j}, d_{3 j}^{+}, d_{3 j}^{-} \geq 0, \quad j=1,2, \ldots, n$

$d_{1}^{-}, d_{1}^{+}, d_{2}^{-}, d_{2}^{+}, d_{3}^{-}, d_{3}^{+} \geq 0$,

where $d_{1}^{+}, d_{1}^{-}$represent the deviation variables for the first goal, $d_{2}^{+}, d_{2}^{-}$denote the deviation variables for the second goal, and $d_{3}^{+}, d_{3}^{-}$show the deviation variables for the third goal, $d_{j}$ is a deviation variable for $\mathrm{DMU}_{\mathrm{j}}, d_{3 j}^{+}, d_{3 j}^{-}$are the unwanted deviation variables for the goal $\left(M-d_{j} \geq 0 \quad j=1,2, \ldots, n\right), M$ is a maximum deviation variable $\left(\max \left\{d_{j}\right\}\right), \varepsilon>0$ is a non-Archimedean element, $D_{r}^{+}$and $D_{i}^{-}$represent any or all of Eqs. (12)-(15), and $X_{i j}$ together with $Y_{r j}$ denote the input and output variables where $X_{i j}=v_{i} x_{i j} \quad \forall i, j$ and $Y_{r j}=u_{r} y_{r j} \quad \forall r, j$.
Moreover, $e_{3}^{*}, e_{2}^{*}, e_{1}^{*}$ are the performance of each of the suppliers for the three economic, social, and environmental criteria are calculated using DEA model with imprecise data (IDEA) i.e., models (11), here, are used as the goals of the new model (18). The results of the output of the model and the required analyses are explained in detail in the next sections.

\section{Research findings}

For the proposed model to be able to be evaluated and the results be viewed, in this section, the results of the model are practiced and analyzed using an example. It should be pointed out that the data of the example are adopted from an article by Azadi et al. (2015) which is the result of a case study of Azar Resin chemical industry company in Qazvin. As it was mentioned in the previous sections, to implement the model in this study, 26 suppliers are evaluated with three economic, social and environmental sets of criteria. Moreover, to cover all dimensions of sustainability, four criteria of human resource policies, reputation, green management system and green image of the suppliers are also employed in this article in addition to the criteria listed in the article to have a better evaluation. In sum, suppliers are evaluated with 10 criteria. Four of them, including the number of the bills without errors, the number of goods delivered in time, the total cost of the product, and the number of the dispatched goods each month, are categorized under economic criteria. Three of them, including human resource policies, reputation, and safety together with human health costs, are placed under social criteria. The last three ones, including green image of the suppliers, environmental management system, and environmental costs, are considered as environmental criteria.

\section{A numerical example}

In this part of the study, the example mentioned in the previous section for the implementation of the proposed model for the supplier selection problem is explained. 26 suppliers and 10 criteria are included which cover all dimensions of sustainability. Following, in Tables 2 and 3, the criteria, variables and the problem data are dealt with.

\section{The output results of the DEA model with imprecise data for economic, social and environmental dimensions}

To evaluate the suppliers economically, socially, and environmentally, first the performance of each of the suppliers for the three economic, social, and environmental criteria are calculated using DEA model with imprecise data (IDEA) i.e., models (11). The outputs of the models which are obtained through GAMS are listed in Table 4, 
Table 2 Criteria for evaluation of sustainable suppliers' performance

\begin{tabular}{ll}
\hline Input & Criteria \\
\hline Economic & \\
$x_{1}$ & Total cost of shipments (TC) (1,000,000 Rials) \\
$x_{2}$ & Number of shipments (NS) \\
Social & Work safety and labor health cost (10,000 Rials) \\
$x_{3}$ & Supplier reputation (SR) (ordinal) \\
$x_{4}$ & Eco-design cost (10,000 Rials) \\
Environmental & Criteria \\
$x_{5}$ & number of the bills received from the supplier \\
\hline Output & without errors (NB) \\
\hline Economic & number of the shipments to arrive on time (NOT) \\
$y_{1}$ & The interests and rights of employees (\%) \\
$y_{2}$ & \\
Social & Supplier's Green Image (SGI) (ordinal) \\
$y_{3}$ & Green Management System (GMS) \\
Environmental & \\
$y_{4}$ & \\
$y_{5}$ &
\end{tabular}

analyzed and compared with others. The performance score obtained in this section is applied in the next part as the inputs of the developed model and is used to determine the actual performance of the suppliers.

The results of Table 4 are needed when a decision maker (DM) wants to evaluate its suppliers separately in terms of economic, social and environmental criteria. Moreover, as a further justification, the evaluation graph in Fig. 1 is presented. But, if the DM wants to have an overall evaluation of its suppliers, a model will be needed that will achieve this evaluation based on the weight of each dimension. Since the economic, social and environmental dimensions are the sustainability dimensions and all the dimensions have a similar impact factor, the only solution is the contrast between multiple objectives. To do so, in the next part, this important fact is achieved based on the developed model.

\section{The results of proposed model}

Most of the DEA models used for supplier evaluation have a single objective and are simple. In real problems, the crucial point is the contrast between multiple objectives in a way that achieving and moving along some of them leads to separation from other objectives. Thus, finding a set of variables that can simultaneously follow all the objectives is rare and difficult, compared to a condition when only one objective is pursued. Therefore, in the present research, according to the concepts of GP model, a model with three sets of economic, social and environmental goals is developed based on which the actual performance of each supplier is selected. In the previous section, the suppliers were evaluated using a DEA model with imprecise data. In the present section, the performance obtained from IDEA model is employed as the economic, social and environmental objectives of model (11). As it was pointed out in the third part, in model (17), the decision variables of the model are $x$ and $y$. Here, the sum of $y$ variables for each supplier will be the performance for that supplier. The results of the evaluation of this model are listed in Table 5 with the value $(\varepsilon=0.01)$.

According to Table 5, the suppliers of National Iranian Oil Company, Esfahan Petrochemical Company, Iran Petrochemical Commercial Company, Razi Petrochemical Company and Laleh Petrochemical Company with performance score of 1 were selected as the best suppliers. This is despite the fact that the performance score of each of these five top suppliers in terms of economic, social and environmental criteria is, respectively, as follows: $(1,1$, $0.4098),(0.7895,1,0.3012),(1,1,0.4808),(0.6526,1,1)$ and $(1,1,1)$. This shows that although, for instance, Esfahan Petrochemical Company has, respectively, achieved the performance scores of $0.7895,1$, and 0.3012 regarding economic, social and environmental criteria, the final status for this company is the performance score 1 which is selected as the top supplier. Furthermore, to have a better interpretation of the results, a chart showing the various performances is presented as Fig. 2 which clearly reflects the importance of the article.

According to Fig. 2, the black line represents the changing trend of the performance based on the developed model (18). In fact, the final and overall evaluation of the suppliers based on this chart can be analyzed. The reason is that although the suppliers are evaluated separately in terms of different dimensions of sustainability, still, if the decision maker wants to evaluate its suppliers in general, a kind of tool will be needed that can evaluate the suppliers generally, considering all dimensions. However, the performance scores of Table 4 are important for the decision maker. In fact, if they are considered as the desirable goals of the decision makers, the employed method should be able to have a general evaluation based on the results of Table 4 and the importance of each of the economic, social and environmental dimensions. The importance of each of these dimensions is not specified, i.e., each of the three sustainability dimensions has somehow the same amount of importance. Thus, the first method which comes to mind is that we calculate the average economic, social and environmental performance for each supplier. This is as if we have the scores of a student in mathematics, chemistry, and physics and we want to calculate the average of the scores for his evaluation. However, since the lessons have 
Table 3 Dataset for 26 suppliers from Azar Resin Chemical Industrial Co. (ARCIC) (Despotis and Smirlis 2002)

\begin{tabular}{|c|c|c|c|c|c|c|c|c|c|c|}
\hline \multirow[t]{2}{*}{ Suppliers } & \multicolumn{5}{|c|}{ Inputs } & \multicolumn{5}{|l|}{ Outputs } \\
\hline & $x 1$ & $x 2$ & $x 3$ & $x 4$ & $x 5$ & $y 1$ & $y 2$ & $y 3$ & $y 4$ & $y 5$ \\
\hline National Iranian Oil Company & 316 & 251 & 18 & 5 & 61 & {$[76,90]$} & {$[199,239]$} & 0.38 & 4 & 4 \\
\hline Shazand Petrochemical Corporation & 281 & 164 & 21 & 10 & 45 & {$[28,42]$} & {$[153,193]$} & 0.6 & 3 & 5 \\
\hline Esfahan Petrochemical Company & 309 & 198 & 40 & 21 & 83 & {$[78,92]$} & {$[203,243]$} & 0.75 & 11 & 5 \\
\hline Farabi Petrochemical Company & 291 & 218 & 45 & 26 & 37 & {$[85,99]$} & {$[167,207]$} & 0.3 & 5 & 4 \\
\hline Iran Petrochemical Commercial Company & 597 & 178 & 29 & 4 & 52 & {$[163,177]$} & {$[197,237]$} & 0.56 & 9 & 3 \\
\hline Alborz Chelic Company & 341 & 142 & 33 & 2 & 19 & {$[129,143]$} & {$[129,169]$} & 0.48 & 1 & 1 \\
\hline Chemical Aland Industrial Group & 475 & 149 & 18 & 8 & 74 & {$[111,125]$} & {$[193,233]$} & 0.69 & 6 & 2 \\
\hline Movalledan Chemical Company & 254 & 172 & 35 & 11 & 53 & {$[250,264]$} & {$[134,174]$} & 0.26 & 2 & 2 \\
\hline Chemical Carbon Acid Company & 328 & 135 & 47 & 22 & 83 & {$[58,72]$} & {$[184,224]$} & 0.64 & 12 & 4 \\
\hline Nima Chemigostar Industrial Co. & 310 & 173 & 16 & 7 & 41 & {$[88,102]$} & {$[113,153]$} & 0.95 & 15 & 3 \\
\hline Gipa Company & 321 & 121 & 45 & 16 & 57 & {$[153,167]$} & {$[125,165]$} & 0.18 & 17 & 2 \\
\hline Farzam Chemical Group & 329 & 204 & 53 & 14 & 38 & {$[90,104]$} & {$[195,235]$} & 0.43 & 8 & 4 \\
\hline Pars Pak Kimia Company & 475 & 212 & 42 & 23 & 32 & {$[139,153]$} & {$[156,196]$} & 0.25 & 24 & 5 \\
\hline Shiraz Petrochemical Company & 259 & 189 & 85 & 13 & 56 & {$[97,111]$} & {$[129,169]$} & 0.58 & 18 & 2 \\
\hline Tabriz Petrochemical Company & 274 & 217 & 51 & 24 & 38 & {$[68,82]$} & {$[85,125]$} & 0.13 & 14 & 4 \\
\hline Razi Petrochemical Company & 264 & 158 & 35 & 17 & 25 & {$[45,59]$} & {$[193,233]$} & 0.62 & 10 & 2 \\
\hline Hegmataneh Petrochemical Company & 327 & 124 & 16 & 1 & 32 & {$[271,285]$} & {$[107,147]$} & 0.33 & 13 & 3 \\
\hline Jam Petrochemical Company & 429 & 207 & 49 & 20 & 57 & {$[46,60]$} & {$[142,182]$} & 0.2 & 22 & 1 \\
\hline Laleh Petrochemical Company & 262 & 138 & 31 & 3 & 25 & {$[173,187]$} & {$[122,162]$} & 0.56 & 19 & 5 \\
\hline Kharg Petrochemical Company & 385 & 238 & 22 & 15 & 74 & {$[119,133]$} & {$[106,146]$} & 0.88 & 7 & 3 \\
\hline Marun Petrochemical Company & 249 & 217 & 72 & 12 & 69 & {$[90,104]$} & {$[150,190]$} & 0.28 & 25 & 5 \\
\hline Karoon Petrochemical Company & 337 & 203 & 33 & 25 & 27 & {$[271,285]$} & {$[104,144]$} & 0.9 & 21 & 2 \\
\hline Khuzestan Petrochemical Company & 365 & 292 & 71 & 9 & 85 & {$[143,157]$} & {$[185,225]$} & 0.8 & 23 & 1 \\
\hline Fajr Petrochemical Company & 296 & 185 & 18 & 18 & 49 & {$[177,191]$} & {$[112,152]$} & 0.7 & 16 & 5 \\
\hline Khorasan Petrochemical Company & 428 & 242 & 22 & 6 & 39 & {$[78,92]$} & {$[94,134]$} & 0.34 & 26 & 3 \\
\hline Mobin Petrochemical Company & 327 & 218 & 48 & 19 & 43 & {$[113,127]$} & {$[173,213]$} & 0.8 & 20 & 4 \\
\hline
\end{tabular}

different degrees of difficulty, i.e., their importance factor is different, the issue of finding the average for the evaluation of the student will arise which will be the accurate and real evaluation. For instance, according to the method of average, the final performance score of Farabi Company will be 0.6638 while according to the developed model, the final performance of this company will be 0.3159 . In this research, if we want to calculate the average, i.e., the actual performance for each supplier, using this method will not be helpful since the importance of each of the sustainability dimensions is not determined. Therefore, in this thesis, to determine the actual performance of each supplier, model (18) is developed which is the DEA model based on GP. The results are presented in Table 5. But, in this research, using this method (calculate the average for each supplier) will not be helpful since the importance of each of the sustainability dimensions is not determined.

\section{Compare the proposed model with the Zhu CCR model (model 11)}

To demonstrate the superiority of the proposed model's discrimination with other similar models, problem data was implemented with 5 inputs and 5 outputs once using the GAM software for model (11). The output results of the models are presented in Table 6.

According to Table 6, the efficiency of model (11) for all companies is 1 . Therefore, it is possible to rank and evaluate companies to zero. This weakness of the model (11) appears when the number of inputs and outputs of the model is high. However, in the developed model this weakness has been resolved and provides an acceptable performance model while comparing the level of goals. 
Table 4 Social, economic and environmental efficiency for 26 suppliers (results of model (11))

\begin{tabular}{|c|c|c|c|}
\hline Suppliers & Social-efficiency & Economic-efficiency & Environmental-efficiency \\
\hline National Iranian Oil Company & 1.0000 & 1.0000 & 0.4098 \\
\hline Shazand Petrochemical Corporation & 0.6316 & 0.9572 & 0.5556 \\
\hline Esfahan Petrochemical Company & 0.7895 & 1.0000 & 0.3012 \\
\hline Farabi Petrochemical Company & 0.3158 & 1.0000 & 0.6757 \\
\hline Iran Petrochemical Commercial Company & 1.0000 & 1.0000 & 0.4808 \\
\hline Alborz Chelic Company & 1.0000 & 1.0000 & 1.0000 \\
\hline Chemical Aland Industrial Group & 0.7263 & 1.0000 & 0.3378 \\
\hline Movalledan Chemical Company & 0.2737 & 1.0000 & 0.4717 \\
\hline Chemical Carbon Acid Company & 0.6737 & 1.0000 & 0.3012 \\
\hline Nima Chemigostar Industrial Co. & 1.0000 & 0.8000 & 0.6098 \\
\hline Gipa Company & 0.1895 & 1.0000 & 0.4386 \\
\hline Farzam Chemical Group & 0.4526 & 1.0000 & 0.6579 \\
\hline Pars Pak Kimia Company & 0.2632 & 0.7932 & 1.0000 \\
\hline Shiraz Petrochemical Company & 0.6105 & 0.9819 & 0.4464 \\
\hline Tabriz Petrochemical Company & 0.1368 & 0.6864 & 0.6579 \\
\hline Razi Petrochemical Company & 0.6526 & 1.0000 & 1.0000 \\
\hline Hegmataneh Petrochemical Company & 1.0000 & 1.0000 & 0.7812 \\
\hline Jam Petrochemical Company & 0.2105 & 0.6882 & 0.5614 \\
\hline Laleh Petrochemical Company & 1.0000 & 1.0000 & 1.0000 \\
\hline Kharg Petrochemical Company & 0.9263 & 0.6140 & 0.3378 \\
\hline Marun Petrochemical Company & 0.2947 & 1.0000 & 0.7101 \\
\hline Karoon Petrochemical Company & 0.9474 & 0.8951 & 1.0000 \\
\hline Khuzestan Petrochemical Company & 0.8421 & 0.9358 & 0.3765 \\
\hline Fajr Petrochemical Company & 0.7368 & 0.8983 & 0.5102 \\
\hline Khorasan Petrochemical Company & 0.7633 & 0.5060 & 1.0000 \\
\hline Mobin Petrochemical Company & 0.8421 & 0.9674 & 0.7054 \\
\hline
\end{tabular}

Fig. 1 Comparison of the economic, social and environmental performance
Comparison of Social, Economic and Environmental efficioncy

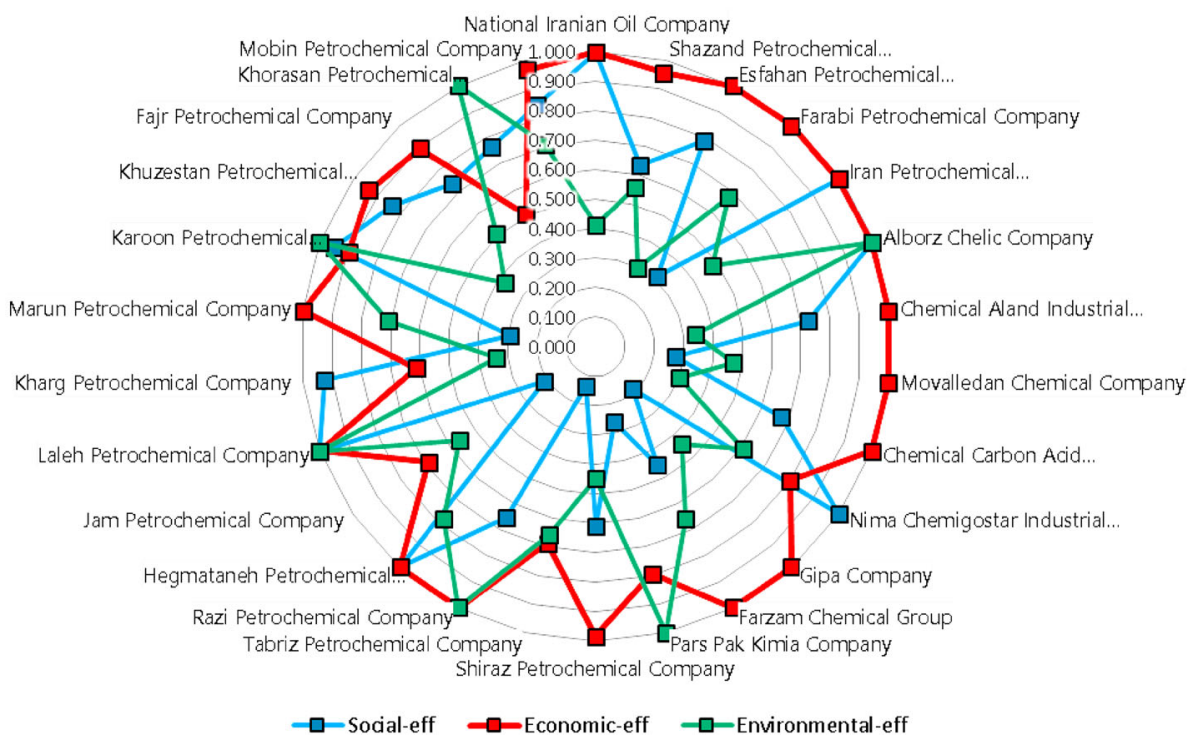


Table 5 Results of model (18) (GP-IDEA) with $(\varepsilon=0 / 01)$

\begin{tabular}{|c|c|c|c|c|c|c|}
\hline Suppliers & $y 1$ & $y 2$ & $y 3$ & $y 4$ & $y 5$ & Efficiency \\
\hline National Iranian Oil Company & 0.7072 & 0.04 & 0.0292 & 0.0231 & 0.2005 & 1.0000 \\
\hline Shazand Petrochemical Corporation & 0.4185 & 0.05 & 0.0462 & 0.0173 & 0.3447 & 0.8767 \\
\hline Esfahan Petrochemical Company & 0.6672 & 0.05 & 0.0577 & 0.0206 & 0.2045 & 1.0000 \\
\hline Farabi Petrochemical Company & 0.0297 & 0.04 & 0.0231 & 0.0236 & 0.1995 & 0.3159 \\
\hline Iran Petrochemical Commercial Company & 0.6854 & 0.03 & 0.0431 & 0.0431 & 0.1984 & 1.0000 \\
\hline Alborz Chelic Company & 0.7603 & 0.01 & 0.0369 & 0.0378 & 0.1549 & 0.9999 \\
\hline Chemical Aland Industrial Group & 0.6266 & 0.02 & 0.0531 & 0.0346 & 0.2148 & 0.9491 \\
\hline Movalledan Chemical Company & 0.01 & 0.02 & 0.02 & 0.0595 & 0.4973 & 0.6068 \\
\hline Chemical Carbon Acid Company & 0.636 & 0.04 & 0.0492 & 0.0155 & 0.2122 & 0.9529 \\
\hline Nima Chemigostar Industrial Co. & 0.6388 & 0.03 & 0.0731 & 0.0255 & 0.1692 & 0.9366 \\
\hline Gipa Company & 0.673 & 0.02 & 0.0138 & 0.0381 & 0.1368 & 0.8817 \\
\hline Farzam Chemical Group & 0.7108 & 0.04 & 0.0331 & 0.0266 & 0.1777 & 0.9882 \\
\hline Pars Pak Kimia Company & 0.4562 & 0.05 & 0.0192 & 0.0379 & 0.3259 & 0.8892 \\
\hline Shiraz Petrochemical Company & 0.1406 & 0.02 & 0.0446 & 0.0645 & 0.4156 & 0.6853 \\
\hline Tabriz Petrochemical Company & 0.3714 & 0.04 & 0.01 & 0.0197 & 0.2168 & 0.6579 \\
\hline Razi Petrochemical Company & 0.726 & 0.02 & 0.0477 & 0.0119 & 0.1944 & 1.0000 \\
\hline Hegmataneh Petrochemical Company & 0.7498 & 0.03 & 0.0254 & 0.0754 & 0.1078 & 0.9884 \\
\hline Jam Petrochemical Company & 0.0587 & 0.01 & 0.0232 & 0.0458 & 0.4545 & 0.5922 \\
\hline Laleh Petrochemical Company & 0.7383 & 0.05 & 0.0431 & 0.0458 & 0.1228 & 1.0000 \\
\hline Kharg Petrochemical Company & 0.0996 & 0.03 & 0.0677 & 0.0614 & 0.3553 & 0.6140 \\
\hline Marun Petrochemical Company & 0.704 & 0.05 & 0.0215 & 0.029 & 0.1483 & 0.9528 \\
\hline Karoon Petrochemical Company & 0.6686 & 0.02 & 0.0692 & 0.0645 & 0.125 & 0.9473 \\
\hline Khuzestan Petrochemical Company & 0.6405 & 0.01 & 0.0615 & 0.0408 & 0.183 & 0.9358 \\
\hline Fajr Petrochemical Company & 0.4954 & 0.05 & 0.0538 & 0.0518 & 0.2472 & 0.8982 \\
\hline Khorasan Petrochemical Company & 0.4318 & 0.03 & 0.0262 & 0.0375 & 0.2378 & 0.7633 \\
\hline Mobin Petrochemical Company & 0.6498 & 0.04 & 0.0615 & 0.0269 & 0.1972 & 0.9754 \\
\hline
\end{tabular}
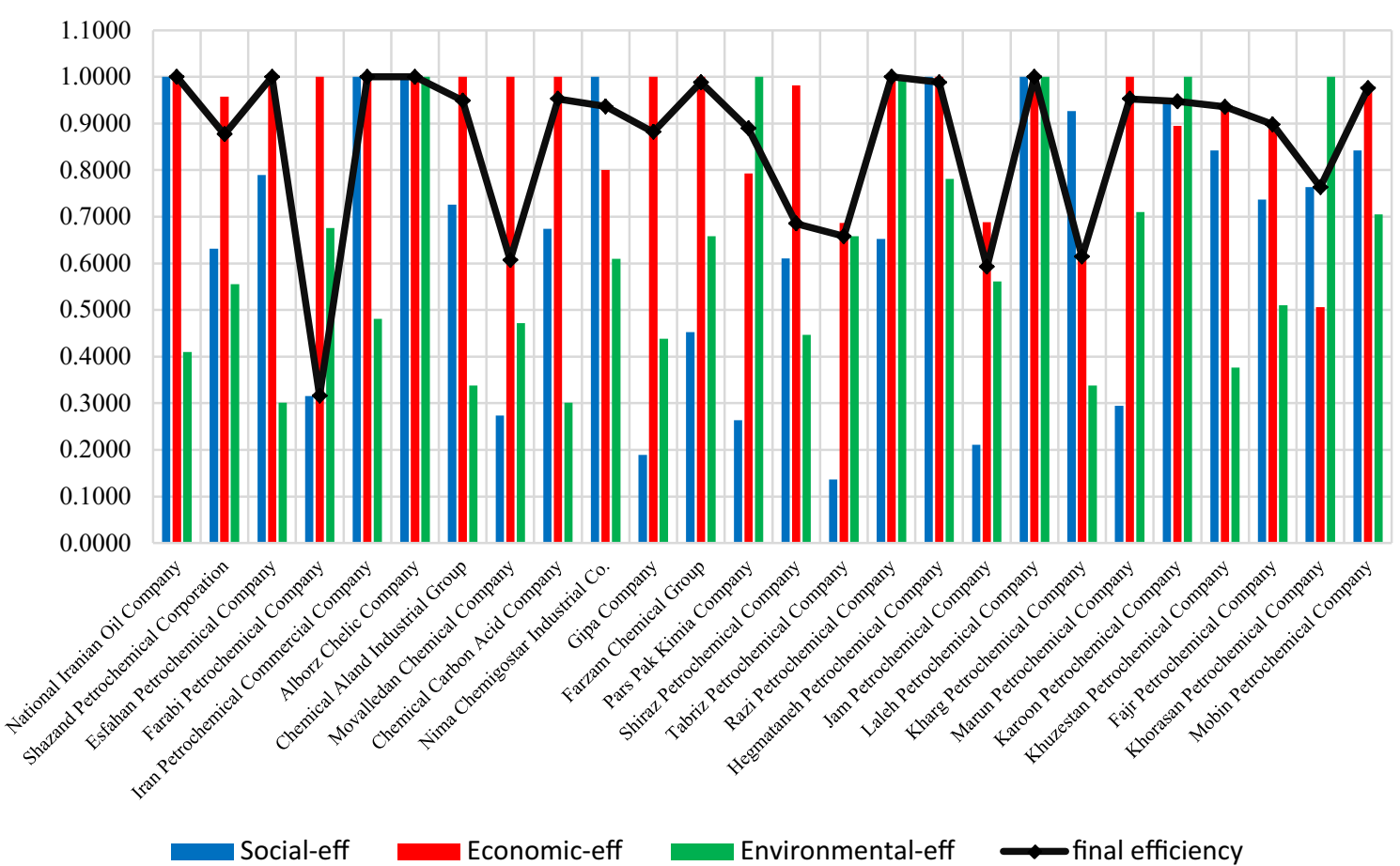

Fig. 2 Showing the procedure of the changes resulting from the developed model in comparison to the economic, social and environmental performance changes 
Table 6 Compare the model developed with the Zhu model (model (11))

\begin{tabular}{lll}
\hline Suppliers & Developed model (GP-IDEA) & Zhu model (model (11)) \\
\hline National Iranian Oil Company & 1.0000 & 1.0000 \\
Shazand Petrochemical Corporation & 0.8767 & 1.0000 \\
Esfahan Petrochemical Company & 1.0000 & 1.0000 \\
Farabi Petrochemical Company & 0.3159 & 1.0000 \\
Iran Petrochemical Commercial Company & 1.0000 & 1.0000 \\
Alborz Chelic Company & 0.9999 & 1.0000 \\
Chemical Aland Industrial Group & 0.9491 & 1.0000 \\
Movalledan Chemical Company & 0.6068 & 1.0000 \\
Chemical Carbon Acid Company & 0.9529 & 1.0000 \\
Nima Chemigostar Industrial Co. & 0.9366 & 1.0000 \\
Gipa Company & 0.8817 & 1.0000 \\
Farzam Chemical Group & 0.9882 & 1.0000 \\
Pars Pak Kimia Company & 0.8892 & 1.0000 \\
Shiraz Petrochemical Company & 0.6853 & 1.0000 \\
Tabriz Petrochemical Company & 0.6579 & 1.0000 \\
Razi Petrochemical Company & 1.0000 & 1.0000 \\
Hegmataneh Petrochemical Company & 0.9884 & 1.0000 \\
Jam Petrochemical Company & 0.5922 & 1.0000 \\
Laleh Petrochemical Company & 1.0000 & 1.0000 \\
Kharg Petrochemical Company & 0.6140 & 1.0000 \\
Marun Petrochemical Company & 0.9528 & 1.0000 \\
Karoon Petrochemical Company & 0.9473 & 1.0000 \\
Khuzestan Petrochemical Company & 0.9358 & 1.0000 \\
Fajr Petrochemical Company & 0.8982 & 1.0000 \\
Khorasan Petrochemical Company & 0.7633 & 1.0000 \\
Mobin Petrochemical Company & 0.9754 & 1.0000 \\
\hline & & \\
\hline
\end{tabular}

\section{Summary and conclusion}

A proper supplier selection and its deep effects on raising the competitive advantage of companies have been broadly deliberated in the literature of SCM. Companies and industries assign more significance to sustainable and green activities in the process of selecting raw material suppliers through raising environmental awareness. Hence, it seems essential to attempt towards development and improvement of decision models that perform the procedure of supplier selection and evaluation more precisely. This paper employs DEA method to assess the comparative efficiency of sustainable supplier selection when there exist cardinal as well as ordinal data. In the first phase, each supplier was evaluated using IDEA model of economic, social and environmental factors, separately. In real terms of business, notable is contrast between the multiple goals, so that access and move to some other cause away from the goal. For this purpose, in the second phase, was developed a new IDEA model based on GP with economic, social, and environmental goals, by which actual performance for each supplier is selected. Merging with the above criteria set, this new model turns into a practical integrated framework of sustainable supplier selection. Also, the use of this model can be incentive for companies to move in the path of economic, social, and environmental activities and adopt a well-rounded sustainable supplier which is able to boost supply chain performance. The problem we studied in the present research is at its preliminary stages of exploration. Further studies can be conducted based on the results of the present article. Comparable studies can be conducted again on treating ordinal and bounded data by fuzzy sets. The further study can be conducted on ranking the sustainable suppliers when there are qualitative, imprecise, as well as stochastic data. Another similar investigation can be repeated for evaluating and selecting sustainable suppliers when there exist dual-role factors. In actual problems, there may exist flexible factors that have the function of inputs as well as outputs. Such variables are known as dual-role factors. In the present research, the suggested model was employed for the problem of supplier selection. The offered model can be applied on other problems including the selection of personnel, international market, and technology. 
Open Access This article is distributed under the terms of the Creative Commons Attribution 4.0 International License (http://crea tivecommons.org/licenses/by/4.0/), which permits unrestricted use, distribution, and reproduction in any medium, provided you give appropriate credit to the original author(s) and the source, provide a link to the Creative Commons license, and indicate if changes were made.

\section{References}

Amindoust A, Ahmed S, Saghafinia A, Bahreininejad A (2012) Sustainable supplier selection: a ranking model based on fuzzy inference system. Appl Soft Comput 12(6):1668-1677

Angulo-Meza L, Lins MPE (2002) Review of methods for increasing discrimination in data envelopment analysis. Ann Oper Res 116(1-4):225-242

Azadi M, Jafarian M, Saen RF, Mirhedayatian SM (2015) A new fuzzy DEA model for evaluation of efficiency and effectiveness of suppliers in sustainable supply chain management context. Comput Oper Res 54:274-285

Bai C, Sarkis J (2010) Integrating sustainability into supplier selection with grey system and rough set methodologies. Int J Prod Econ 124(1):252-264

Bal H, Örkcü HH, Çelebioğlu S (2010) Improving the discrimination power and weights dispersion in the data envelopment analysis. Comput Oper Res 37(1):99-107

Banker RD, Charnes A, Cooper WW (1984) Some models for estimating technical and scale inefficiencies in data envelopment analysis. Manag Sci 30(9):1078-1092

BüyükÖzkan G, Çifçi G (2011) A novel fuzzy multi-criteria decision framework for sustainable supplier selection with incomplete information. Comput Ind 62(2):164e174

Charnes A, Cooper WW, Rhodes E (1978) Measuring the efficiency of decision making units. Eur J Oper Res 2(6):429-444

Dao V, Langella I, Carbo J (2011) From green to sustainability: information Technology and an integrated sustainability framework. J Strateg Inf Syst 20(1):63-79

Despotis DK, Smirlis YG (2002) Data envelopment analysis with imprecise data. Eur J Oper Res 140(1):24-36

Dyllick T, Hockerts K (2002) Beyond the business case for corporate sustainability. Bus Strategy Environ 11(2):130-141

Govindan K, Khodaverdi R, Jafarian A (2013) A fuzzy multi criteria approach for measuring sustainability performance of a supplier based on triple bottom line approach. J Clean Prod 47:345-354

Govindan K, Rajendran S, Sarkis J, Murugesan P (2015) Multi criteria decision making approaches for green supplier evaluation and selection: a literature review. J Clean Prod 98:66-83

Guneri AF, Yucel A, Ayyildiz G (2009) An integrated fuzzy-lp approach for a supplier selection problem in supply chain management. Expert Syst Appl 36(5):9223-9228

Karpak B, Kumcu E, Kasuganti RR (2001) Purchasing materials in the supply chain: managing a multi-objective task. Eur J Purch Supply Manag 7(3):209-216

Kim S-H, Park C-G, Park K-S (1999) An application of data envelopment analysis in telephone offices evaluation with partial data. Comput Oper Res 26(1):59-72
Kleinsorge IK, Schary PB, Tanner RD (1992) Data envelopment analysis for monitoring customer-supplier relationships. J Account Public Policy 11(4):357-372

Kokangul A, Susuz Z (2009) Integrated analytical hierarch process and mathematical programming to supplier selection problem with quantity discount. Appl Math Model 33(3):1417-1429

Kumar M, Vrat P, Shankar R (2004) A fuzzy goal programming approach for vendor selection problem in a supply chain. Comput Ind Eng 46(1):69-85

Kumar A, Jain V, Kumar S (2014) A comprehensive environment friendly approach for supplier selection. Omega 42(1):109-123

Li X-B, Reeves GR (1999) A multiple criteria approach to data envelopment analysis. Eur J Oper Res 115(3):507-517

Liu F-HF, Hai HL (2005) The voting analytic hierarchy process method for selecting supplier. Int J Prod Econ 97(3):308-317

Motwani J, Youssef M, Kathawala Y, Futch E (1999) Supplier selection in developing countries: a model development. Integr Manuf Syst 10(3):154-162

Nourmohamadi Shalke P, Paydar MM, Hajiaghaei-Keshteli M (2017) Sustainable supplier selection and order allocation through quantity discounts. Int J Manag Sci Eng Manag. https://doi. org/10.1080/17509653.2016.1269246

Ordoobadi SM (2009) Development of a supplier selection model using fuzzy logic. Supply Chain Manag Int J 14(4):314-327

Saen RF (2007) Suppliers selection in the presence of both cardinal and ordinal data. Eur J Oper Res 183(2):741-747

Saen RF (2009) A decision model for ranking suppliers in the presence of cardinal and ordinal data, weight restrictions, and nondiscretionary factors. Ann Oper Res 172(1):177-192

Seuring S, Müller M (2008) From a literature review to a conceptual framework for sustainable supply chain management. J Clean Prod 16(15):1699-1710

Talluri S, Narasimhan R (2003) Vendor evaluation with performance variability: a max-min approach. Eur J Oper Res 146(3):543-552

Talluri S, Ram N, Anand N (2006) Vendor performance with supply risk: a chance-constrained DEA approach. Int $\mathrm{J}$ Prod Econ 100(2):212-222

Ting S-C, Cho DI (2008) An integrated approach for supplier selection and purchasing decisions. Supply Chain Manag Int $\mathbf{J}$ 13(2):116-127

Toloo M, Nalchigar S (2011) A new DEA method for supplier selection in presence of both cardinal and ordinal data. Expert Syst Appl 38(12):14726-14731

Weber CA, Current JR, Desai A (1998) Non-cooperative negotiation strategies for vendor selection. Eur J Oper Res 108(1):208-223

Weber CA, Current J, Desai A (2000) An optimization approach to determining the number of vendors to employ. Supply Chain Manag Int J 5(2):90-98

Wen L, Xu L, Wang R (2013) Sustainable supplier evaluation based on intuitionistic fuzzy sets group decision methods. J Inf Comput Sci 10(10):3209-3220

Zhu J (2003) Imprecise data envelopment analysis (IDEA): a review and improvement with an application. Eur J Oper Res 144:513-529 